\title{
Demanstan korunma
}

\section{Preventing dementia}

Pınar Tosun Taşar

Ege Üniversitesi Tıp Fakültesi, İç Hastalıkları Anabilim Dalı, Geriatri Bilim Dalı, İzmir

\section{Öz}

Demans; öğrenme, bellek, oryantasyon, dil fonksiyonları ile kişilik gibi mental fonksiyonların bozulması ile karakterize; sosyal ve iş hayatını olumsuz etkileyen, merkezi sinir sisteminin sinsi ve progresif, nörodejeneratif bir hastalığıdır. Alzheimer hastalığı tüm demans vakalarının \%50-80'ini oluşturmaktadır ve oranı yaşlanmayla birlikte giderek artmaktadır. Demansın etiyopatolojisinde oksidadif stres, inflamasyon, vasküler, genetik ve çevresel, yaşam tarzıyla ilişkili olan faktörlerin etkili olduğu gösterilmiştir. Demansın önlenmesi ya da geciktirilmesi ile bireye aileye ve topluma olan sosyal ve ekonomik yük azaltılacaktır. Bu derlemede, demanstan korunmada yapıımış gözlemsel çalışmaların, yaşam tarzı ile ilgili değişimlerin, farmakolojik çalışmaların gözden geçirilmesi amaçlanmıştır.

Anahtar Sözcükler: Demans, korunma, yaşlanma.

\section{Abstract}

Dementia is an insidious and progressive neurodegenerative disorder of the central nervous system characterized by the decline of mental functions including learning, balance, orientation, language, and personality, and it affects a patient's social and professional lives. Alzheimer's disease accounts for 50-80\% of all dementia cases, and the rate increases with age. Oxidative stress, inflammation, vascular, genetic and environmental factors, and lifestyle have been shown to affect the etiopathology of dementia. Preventing or delaying dementia would reduce its social and economic burden. In this review, we aimed to evaluate observational studies, variables associated with lifestyle, and pharmacological studies regarding the prevention of dementia.

Keywords: Dementia, prevention, aging.

\section{Giriş}

Demans; öğrenme, bellek, oryantasyon, dil fonksiyonları ile kişilik gibi mental fonksiyonların bozulması ile karakterize, sosyal ve iş hayatının etkileyen, merkezi sinir sisteminin sinsi ve progresif, nörodejeneratif bir hastalığıdır. Alzheimer hastalığı (AH) tüm demans vakalarının \% 50-80'ini oluşturmakta ve sayısı giderek artmaktadır. Demans ve $\mathrm{AH}$ hastalığı multifaktöriyel hastalıklar arasındadır, son yıllarda yapılmış olan çalışmalarda AH'ın etiyolojisinde oksidadif stres, inflamasyon, vaskuler, genetik ve çevresel, yaşam tarzıyla ilişkili olan faktörlerin etkili olduğu gösterilmiştir. $\mathrm{AH}$ hastalığının tam olarak patofizyolojisi bilinmemekle birlikte patogenizinde nöronlar arasında beta-amiloid proteini $(A ß)$ ve nörofibriller yumak birikiminin rol oynadığı gösterilmiştir, tüm bunlar sinaptik aralıkta nörotransmitter ve nöron kaybına yol açmaktadır $(1,2)$.

\section{Yazışma Adresi: Pınar TOSUN TAŞAR}

Ege Üniversitesi Tıp Fakültesi, İç Hastalıkları Anabilim Dalı, Geriatri Bilim Dalı, 35100 Bornova, IZMiR
Demans ve $\mathrm{AH}$ için günümüzde kullanılan ilaçların etkileri sınırlı olup, mevcut tedaviler gerçek manada hastalığın seyrini çok fazla etkileyememektedir $\mathrm{Bu}$ nedenle demansı önlemek ya da gecikmesini sağlamak sosyal ve ekonomik olarak yükü azaltacaktır (3).

Demans ve AH'da değiştirilemez risk faktörleri arasında ileri yaş, homozigot ya da heterozigot apolipoprotein $E$ (APOE) $\varepsilon 4$ allel varlığı, presenilin (PSEN1), presenilin 2 (PSEN2) ve amiloid prekürsör protein (APP) pozitifliği gibi genetik yatkınlık yapacak olan genlerin varlığı, aile hikayesi, down sendromudur (4-7). Değiştirilebilir risk faktörleri ise hipertansiyon, diabetes mellitus, obezite, inme, kardiyovasküler hastalık varlığı ve sigara kullanımıdır (8)

Literatürde demanstan koruyucu yaklaşımlar genellikle 65 yaş ve sonrası geç başlangıçlı AH'da mevcut iken, farmakolojik çalışmalar ise daha çok erken başlangıçlı (65 yaş ve öncesi) demans hastalarında yapılmaktadır. Derlememizde, demans ve AH'da korunmada yapılmış yaşam tarzı ile ilgili değişimleri, gözlemsel çalışmaları, farmakolojik çalışmaları gözden geçirmeyi amaçladık. 


\section{Yaşam Tarzı İle İlgili Değişimler}

\section{Vitamin Destek Tedavisi}

\subsection{Antioksidan Vitaminler}

$\mathrm{Bu}$ konuda yapılmış çeşitli çalışmalar mevcuttur. Yaşlılarda Vitamin E replasmanının kognitif fonksiyonlar üzerine etkisinin gösterildiği bir çalışmada 10 yıllık izlem ile vitamin replasmanının kognitif fonksiyonlar üzerine herhangi bir etkisinin olmadığı gösterilmiştir $(9,10)$. Diğer bir antioksidan olan beta-karotenin 4052 yaşlı arasında 18 yıllık izlemi ile yapılan diğer bir çalışmada da kognitif fonksiyonlar üzerine etkisi gösterilememiştir (11).

\subsection{Vitamin B6, B12 ve Folik Asit}

Serum homosistein düzeyindeki artış, düşük folik asit, vitamin B6, vitamin B12 düzeyindeki düşüklüğün kognitif fonksiyonlarda azalma yaptığı ve demanstan koruduğu düşünülmektedir. Ancak 22000 hastanın katıldığı toplam 11 randominize kontrollü çalışmanın dahil edildiği bir meta-analizde ise B vitamini replasmanının serum homosistein düzeylerini azalttığı; ancak kognitif fonksiyonlara herhangi bir etkisinin olmadığı gösterilmiştir (12).

\subsection{Vitamin D}

Vitamin D eksikliği ile yaşı ı hastalarda kognitif fonksiyonları azalttığını gösteren kanıta dayalı çalışmalar mevcut iken henüz etkisi tam olarak belli değildir (13).

\subsection{Omega-3 Yağ Asitleri}

Balık alımı ve omega-3 yağ asitlerinin kardiyovasküler hastalıklar hastalıklarda olumlu etkisi gösterilmiştir. Yapılan kesitsel bir çalışmada Omega-3 yağ alımının ise $\mathrm{AH}$ belirteci olan beta-amiloid birikimini azalttığı gösterilmiştir (14).

\subsection{Meyve ve Sebze Alımı}

Yüksek miktarda sebze ve meyve alımının kognitif fonksiyonları iyileştirdiği gösterilmiştir. 1836 yaşlının katıldığı bir çalışmada meyve ve sebze alanlarda yedidokuz yıllık izlemde demans görülme olasılığının azaldığı (15), iki büyük gözlemsel, prospektif çalışmada ise sebze tüketenlerde kognitif fonksiyonlardaki bozulmanın daha az olduğu gösterilmiştir (16).

\section{Fiziksel Aktivite}

Düzenli fiziksel aktivitenin serebral kan akımını düzenlenmesi, kan basıncını düşürmesi, lipid düzeylerini azaltması gibi birçok risk faktörü üzerine olumlu etkileri vardır. Her ne kadar randomize kontrollü çalışmalarda güçlü kanıtlar söz konusu olmasa da fiziksel aktivitenin kognitif fonksiyonları iyileştirdiği ve demans riskini azalttığı gösterilmiştir $(17,18)$.

\section{Akdeniz Tipi Diyet}

Akdeniz tipi diyetle beslenenlerde $A H^{\prime} ı n$ daha yavaş olarak seyrettiği gösterilmiştir $(19,20)$. Yine yapılmış olan kohort çalışmada akdeniz tipi diyetle beslenenlerde kardiyovasküler olayların ve inmenin daha az görüldüğü ve demans riskini azalttığı gösterilmiştir $(21,22)$.

Yaşam tarzındaki değişiklikler, hipertansiyon, obezite, diabetes mellitusun tedavisi ve fiziksel aktivite yaklaşık olarak \%10-25 arasında da hastalığın oluşmasını geciktirecek ya da ilerlemesini engelleyecektir (23) .

\section{Farmakolojik Tedavi Yöntemleri}

\section{Anti-hipertansif Tedaviler}

İleri yaş hipertansiyonu ve demans arasındaki ilişkiler çelişkilidir. Bazı çalışmalarda ileri yaşta hipotansiyonunun demans ve AH'ını kolaylaştırdığı $(24,25)$, bazı yayınlarda da hipertansiyonu olup, antihipertansif kullananlarda nöritik plak ve nörofibriller yumağı azalttığı gösterilmiştir (26).

\section{Hormonoterapi}

Her ne kadar epidemiyolojik çalışmalarda östrojen replasmanının demansı önlediği belirtilse de (27), yapılmış diğer çalışmalarda östrojen replasmanının demans riskini arttığı gösterilmiştir $(28,29)$.

Dehidroepiandrosterone (DHEA) adrenal bezden salınan, erişkinlik döneminde pik yapan ve daha sonra düzeyi azalan bir hormondur. DHEA ile yapılmış olan çalışmalarda hormon replasmanının demans riskini azaltmadığı gösterilmiştir (30).

\section{Non-steroid Antiinflamatuvar İlaç Kullanımı}

Non-steroid antiinflamatuvar (NSAI) ilaç kullanımı ve demans arasındaki ilişkiler çelişkilidir. Bazı epidemiyolojik çalışmalarda NSAI kullanımının amiloid proteini olan Abeta42 proteinini azaltarak AH'dan koruduğu ve kognitif fonksiyonları iyileştirdiği gösterilmiştir (31,32). Ancak diğer bir kohort çalışmasında ise NSAI kullanımının AH'ı arttırdığı gösterilmiştir (33), otopsi verilerinde de yüksek dozda NSAl kullananlarda nöritik plakların daha fazla olduğu gösterilmiştir (34). Diğer yapılmış bir çalışmada da NSAI ilaçlardan ibuprofen, indometazin, sulindak'ın Abeta42'yi azalttığı ancak naproxen, etodolakın ise amiloid birikimi üzerine etkili olmadığı gösterilmiştir $(35,36)$. Ailesinde en az bir veya daha $\mathrm{AH}$ yakını olanlarda da COX-2 selektif inhibitörlerinin kullanıldığı diğer bir çalışmada da bu ilacın kognitif fonksiyonlar üzerine her hangi bir etkisi olmadığı gösterilmiştir (37).

\section{Statinler}

Toplam 6992 yaşlının katıldığı Rotterdam çalışmasında statin kullanımının kognitif fonksiyonları iyileştirdiği gösterilmiştir (38). Ancak diğer iki büyük randominize kontrollü çalışmada ise statinlerin kognitif fonksiyonlar üzerine ise her hangi bir etkisinin olmadığı gösterilmiştir $(39,40)$.

\section{Gözlemsel Çalışmalar}

Omega-3, unsature yağ asitleri, antioksidanlar, vitamin, ılımlı alkol alımı protektif nutrisyonel komponentler de 
demansdan korunmada önemlidir $(41,42)$. Yalnızlık hissi, depresyon, sosyal izolasyon ve psikososyal stres $\mathrm{AH}$ için risk faktörleri arasındadır. Yüksek eğitim düzeyi, egzersiz, kognitif ve sosyal olarak stimülasyonda demansdan koruyucu faktörler arasındadır $(8,43)$.

\section{Devam Eden Çok- Merkezli Koruyucu Çalışmalar}

$\mathrm{Bu}$ konuda halen devam eden FINGER (Finnish Geriatric Intervention Study to Prevent Cognitive Impairment and Disability), MAPT (Multidomain Alzheimer Prevention Trial), PreDIVA (Prevention of Dementia by Intensive Vascular Care) olmak üzere üç çalışma mevcuttur (44-47). Çalışmaların özeti Tablo-1'de sunulmuştur.

\section{Devam Eden Müdahale Çalışmalar}

$A ß$ proteinin önemi anlaşıldıktan sonra bu konuda bazı çalışmalar yapılmıştır. API-ADAD (Autosomal Dominant Alzheimer's Disease treatment trial), Dominantly Inherited Alzheimer's Network (DIAN), Anti-Amiloid Treatment in Asypptomatic Alzheimer's Disease (ADCSA4) $(48,49)$. Çalışmaların özeti Tablo-2'de sunulmuştur.

Sonuç olarak, demansın önlenmesinde henüz etkin bir tedavi yöntemi yoktur. Yapılmış çalışmalarda nonfarmakolojik yöntemlerden Akdeniz tipi diyetin ve fiziksel egzersizin etkinliği kanıtlanmıştır. Diğer gözlemsel ve müdahale çalışmalarının ise sonuçları beklenmektedir.

Tablo-1. Devam Eden Çok Merkezli Koruyucu Çalışmalar (5)*

\begin{tabular}{|c|c|c|c|}
\hline & FINGER & MAPT & PreDIVA \\
\hline 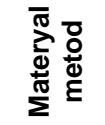 & $\begin{array}{l}\text { Toplumda yaşayan } 60-77 \text { yaşları } \\
\text { arasında toplam } 1260 \text { yaşlı arasında } \\
\text { yapılmıştır. }\end{array}$ & $\begin{array}{l}\text { Toplumda yaşayan } 70 \text { yaş ve üzeri } \\
\text { toplam } 1680 \text { yaşlı arasında } \\
\text { yapılmıştır. }\end{array}$ & $\begin{array}{l}\text { Toplumda yaşayan } 70-78 \text { yaş arası } \\
3533 \text { yaşlı arasında yapılmıştır. }\end{array}$ \\
\hline 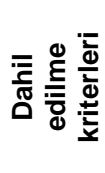 & $\begin{array}{l}\text { CAIDE demans risk skorlaması } \\
\text { yapılmış, ve skordan } 6 \text { ve üzeri } \\
\text { alanlar çalışmaya dahil edilmiştir. }\end{array}$ & $\begin{array}{l}\text { Mini-mental skoru } 24 \text { ve üzeri olan, } \\
\text { yürüme hızı düşük, günlük yaşam } \\
\text { aktivitelerinin en az birinde yarı } \\
\text { bağımlı ya da tam bağımlı olan } \\
\text { kırılgan yaşlılar arasında yapıımıştır. }\end{array}$ & $\begin{array}{l}\text { Toplumda yaşayan Mini-mental skoru } \\
\text { 23'ün üzerinde olanlar çalışmaya dahil } \\
\text { edilmiştir. }\end{array}$ \\
\hline 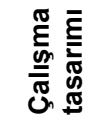 & $\begin{array}{l}\text { Çok-merkezli randomize-kontrollü } \\
\text { çalışmadır. }\end{array}$ & $\begin{array}{l}\text { Çok-merkezli randomize-kontrollü } \\
\text { çalışmadır. }\end{array}$ & Çok-merkezli-kontrollü çalışmadır. \\
\hline $\begin{array}{l}\frac{0}{\pi} \\
\frac{0}{\pi} \\
\frac{\pi}{2} \\
\sum\end{array}$ & $\begin{array}{l}\text { Nutrisyonel destek, fiziksel aktivite, } \\
\text { kognitif çalışmalar, sosyal aktivitenin } \\
\text { arttırılması, metabolik ve vasküler } \\
\text { risk faktörlerinin yönetimi gibi } \\
\text { önerilerde bulunulmuştur. } \\
\text { Kontrol grubuna ise yalnızca düzenli } \\
\text { egzersiz yaptırılmıştır. }\end{array}$ & $\begin{array}{l}\text { Kişiler dört gruba ayrılmıştır: } \\
\text { 1. Omega-3 desteği verilmiştir. } \\
\text { 2. Yaşam tarzı değişimi önerilmiştir. } \\
\text { 3. Omega-3 desteği verilmiş+yaşam } \\
\text { tarzı değişimi önerilmiştir. } \\
\text { 4. Plasebo verilmiştir. }\end{array}$ & $\begin{array}{l}\text { Nutrisyonel destek, fiziksel aktivite, } \\
\text { kognitif çalışmalar, sosyal aktivitenin } \\
\text { arttırılması, metabolik ve vasküler risk } \\
\text { faktörlerinin yönetimi gibi önerilerde } \\
\text { bulunulmuştur. }\end{array}$ \\
\hline 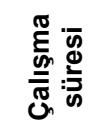 & $2-5$ yıl & $3-5 \mathrm{yll}$ & $6 \mathrm{yll}$ \\
\hline$\frac{\text { E }}{\frac{\text { I }}{c}}$ & $\begin{array}{l}\text { Primer: Kognitif fonksiyonlardaki } \\
\text { değişim } \\
\text { Sekonder: Demans, kardiyovasküler } \\
\text { olaylar, depresyon, yaşam kalitesi, } \\
\text { AH belirteçlerindeki değişim }\end{array}$ & $\begin{array}{l}\text { Primer: Kognitif fonksiyonlardaki } \\
\text { değişim } \\
\text { Sekonder: Mini-mental-CDR } \\
\text { skorundaki değişim, fonksiyonel } \\
\text { durum, depresyon, AH } \\
\text { belirteçlerindeki değişim }\end{array}$ & $\begin{array}{l}\text { Primer: Demans, sakatlık } \\
\frac{\text { Sekonder: Depresyon, kardiyovasküler }}{\text { olaylar }}\end{array}$ \\
\hline
\end{tabular}

*AH: Alzheimer hastalığı, CAIDE: Cardiovascular risk factors, aging and dementia, CDR: Clinical dementia rating. 
Tablo-2. Devam Eden Müdahale Çalışmaları (5)*.

\begin{tabular}{|c|c|c|c|}
\hline & API & DIAN & ADCS-A4 \\
\hline 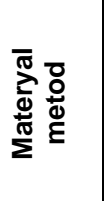 & $\begin{array}{l}\text { Kolombiya'da PSEN1 mutasyonu } \\
\text { olan 30-60 yaş grubu arasındaki } \\
300 \text { asemptomatik kişi arasında } \\
\text { yapıımıştır. Ayrıca DIAN çalışma } \\
\text { grubundan da kişiler çalışmaya } \\
\text { dahil edilmiştir. }\end{array}$ & $\begin{array}{l}\text { Erken başlangıçlı demans hastalarının } \\
18-80 \text { yaşları arasında } 210 \text { yakını } \\
\text { çalışmaya dahil edilmiştir. Çalışmaya } \\
\text { dahil edilenler tamamen sağlıklı ya da } \\
\text { hafif derecede kognitif bozukluğu olanlar } \\
\text { arasından seçilmiştir. }\end{array}$ & $\begin{array}{l}65-85 \text { yaşları arasında kognitif } \\
\text { fonksiyonları normal olan } 1150 \text { yaşlı } \\
\text { arasında yapılmıştır. }\end{array}$ \\
\hline 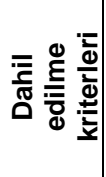 & $\begin{array}{l}\text { PSEN1 mutasyonu olanlar } \\
\text { çalışmaya dahil edilmiştir. Ayrıca } \\
\text { gen mutasyonu olmayanlar da çift } \\
\text { kör olarak çalışmaya dahil } \\
\text { edilmiştir. }\end{array}$ & $\begin{array}{l}\text { PSEN1, PSEN2 ya da APP mutasyonu } \\
\text { olan } 105 \text { taşıyıcı, } 105 \text { kontrol grubu } \\
\text { çalışmaya dahil edilmiştir. }\end{array}$ & $\begin{array}{l}\text { PET'de amiloid birikimi olan ve } \\
\text { olmayan bireyler dahil edilmiştir. }\end{array}$ \\
\hline 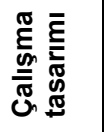 & $\begin{array}{l}\text { Faz II, randomize, çift kör, plasebo } \\
\text { kontrollü }\end{array}$ & $\begin{array}{l}\text { Faz II/III randomize, çift kör, plasebo } \\
\text { kontrollü çalışma }\end{array}$ & $\begin{array}{l}\text { Faz III randomize, çift kör, plasebo } \\
\text { kontrollü }\end{array}$ \\
\hline 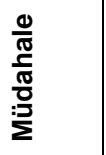 & $\begin{array}{l}\text { Anti-amiloid monoklonol antikor } \\
\text { (Crenezumab) }\end{array}$ & $\begin{array}{l}\text { İki anti-amiloid antikor (Gantenerumab ve } \\
\text { Solanezumab) }\end{array}$ & $\begin{array}{l}\text { Anti-amiloid monoklonol antikor } \\
\text { (Solanezumab) }\end{array}$ \\
\hline 蛋 & $\begin{array}{l}5 \text { yıl (ara değerlendirme ikinci } \\
\text { yılda yapılmıştır) }\end{array}$ & $2+3$ yıl uzatma & $3+2$ yıl uzatma \\
\hline 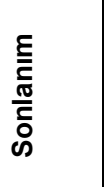 & $\begin{array}{l}\text { Primer: Kognitif fonksiyonlarda } \\
\text { bozulma } \\
\text { Sekonder: AH belirteçlerindeki } \\
\text { değişim, beyindeki amiloid } \\
\text { yükünde artış ve beyinde atrofi }\end{array}$ & $\begin{array}{l}\text { Bašlangıç fazı (2 yıl): AH belirteçlerindeki } \\
\text { değişim, serebrospinal sıvı içerisindeki } \\
\text { amiloid birikimi } \\
\text { İlem (3 yıl): Kognitif fonksiyonlar } \\
\text { açısından takip }\end{array}$ & $\begin{array}{l}\text { Primer: Kognitif fonksiyonlar } \\
\frac{\text { Sekonder: AH belirteçlerindeki }}{\text { değişim }}\end{array}$ \\
\hline$\frac{\text { 돈 }}{3}$ & 2013'de başlamıştır. & 2012'de başlamıştır. & 2014'de başlamıştır. \\
\hline
\end{tabular}

*AH: Alzheimer hastalığı, APP: Amiloid prekürsör protein, PET: Pozitron emisyon tomografi, PSEN: presenilin.

\section{Kaynaklar}

1. Wyss-Coray T, Rogers J. Inflammation in Alzheimer disease-a brief review of the basic science and clinical literature. Cold Spring Harb Perspect Med 2012;2(1):a006346.

2. Orsucci $D$, Mancuso $M$, lenco EC, et al. Vascular factors and mitochondrial dysfunction: a central role in the pathogenesis of Alzheimer's disease. Curr Neurovasc Res 2013;10(1):76-80.

3. Ferri CP, Prince M, Brayne C, et al. Global prevalence of dementia: a Delphi consensus study. Lancet 2005;366(9503): 2112-7.

4. World Health Organization (WHO). (homepage on the internet) Dementia:a public health priority. Geneva:World Health Organization- Alzheimer's Disease International 2012 (updated 2015; cited May 2015). Available from: http://www.who.int/mental_health/publications/dementia_report_2012/en/.

5. Solomon A, Mangialasche F, Richard E, et al. Advances in the prevention of Alzheimer's disease and dementia. J Intern Med 2014;275(3):229-50.

6. Qiu C, Kivipelto M, Agüero-Torres H, Winblad B, Fratiglioni L. Risk and protective effects of the APOE gene towards Alzheimer's disease in the Kungsholmen project: variation by age and sex. J Neurol Neurosurg Psychiatry 2004;75(6):828-33.

7. Slooter AJ, Cruts M, Kalmijn S, et al. Risk estimates of dementia by apolipoprotein E genotypes from a population-based incidence study: the Rotterdam Study. Arch Neurol 1998;55(7):964-8.

8. Mangialasche F, Kivipelto M, Solomon A, Fratiglioni L. Dementia prevention: current epidemiological evidence and future perspective. Alzheimers Res Ther 2012;4(1):6.

9. Yaffe $\mathrm{K}$, Clemons TE, McBee WL, et al. Impact of antioxidants, zinc, and copper on cognition in the elderly: a randomized, controlled trial. Neurology 2004;63(9):1705-7.

10. Kang JH, Cook NR, Manson JE, et al. Vitamin E, vitamin C, beta carotene, and cognitive function among women with or at risk of cardiovascular disease: The Women's Antioxidant and Cardiovascular Study. Circulation 2009;119(21):2772-80.

11. Yaffe K. Antioxidants and prevention of cognitive decline: does duration of use matter? Arch Intern Med 2007;167(20):2167-8. 
12. Clarke R, Bennett $D$, Parish $S$, et al. Effects of homocysteine lowering with $B$ vitamins on cognitive aging: meta-analysis of 11 trials with cognitive data on 22,000 individuals. Am J Clin Nutr 2014;100(2):657-66.

13. Balion C, Griffith LE, Strifler L, et al. Vitamin D, cognition, and dementia: a systematic review and meta-analysis. Neurology 2012;79(13):1397-405.

14. Gu Y, Schupf N, Cosentino SA, Luchsinger JA, Scarmeas N. Nutrient intake and plasma beta-amyloid. Neurology 2012;78(23):1832-40.

15. Dai Q, Borenstein AR, Wu Y, Jackson JC, Larson EB. Fruit and vegetable juices and Alzheimer's disease: the Kame Project. Am J Med 2006;119(9):751-9.

16. Morris MC, Evans DA, Tangney CC, Bienias JL, Wilson RS. Associations of vegetable and fruit consumption with age-related cognitive change. Neurology 2006;67(8):1370-6.

17. Rovio S, Kåreholt I, Helkala EL, et al. Leisure-time physical activity at midlife and the risk of dementia and Alzheimer's disease. Lancet Neurol, 2005. 4(11):705-11.

18. Larson EB, Wang L, Bowen JD, et al. Exercise is associated with reduced risk for incident dementia among persons 65 years of age and older. Ann Intern Med 2006;144(2):73-81.

19. Scarmeas N, Stern Y, Mayeux R, et al. Mediterranean diet and mild cognitive impairment. Arch Neurol 2009;66(2):216-25

20. Psaltopoulou T, Sergentanis TN, Panagiotakos DB, et al. Mediterranean diet, stroke, cognitive impairment, and depression: A meta-analysis. Ann Neurol 2013;74(4):580-91.

21. Estruch R, Ros E, Salas-Salvadó J, et al. Primary prevention of cardiovascular disease with a Mediterranean diet. N Engl J Med 2013;368(14):1279-90.

22. Widmer RJ, Flammer AJ, Lerman LO, Lerman A. The Mediterranean diet, its components, and cardiovascular disease. Am $J$ Med 2015;128(3):229-38.

23. Smith AD, Yaffe K. Dementia (including Alzheimer's disease) can be prevented: statement supported by international experts. $J$ Alzheimers Dis 2014;38(4):699-703.

24. Verghese J, Lipton RB, Hall CB, Kuslansky G, Katz MJ. Low blood pressure and the risk of dementia in very old individuals. Neurology 2003;61(12):1667-72.

25. Morris MC, Scherr PA, Hebert LE, et al. Association of incident Alzheimer disease and blood pressure measured from 13 years before to 2 years after diagnosis in a large community study. Arch Neurol 2001;58(10):1640-6.

26. Hoffman LB, Schmeidler J, Lesser GT, et al. Less Alzheimer disease neuropathology in medicated hypertensive than nonhypertensive persons. Neurology 2009;72(20):1720-6.

27. LeBlanc ES, Janowsky J, Chan BK, Nelson HD. Hormone replacement therapy and cognition: systematic review and metaanalysis. JAMA 2001;285(11):1489-99

28. Shumaker SA, Legault C, Rapp SR, et al. Estrogen plus progestin and the incidence of dementia and mild cognitive impairment in postmenopausal women: the Women's Health Initiative Memory Study: a randomized controlled trial. JAMA 2003;289(20):2651-62.

29. Schneider LS. Estrogen and dementia: insights from the Women's Health Initiative Memory Study. JAMA 2004;291(24):3005-7.

30. Grimley Evans J, Malouf R, Huppert F, van Niekerk JK. Dehydroepiandrosterone (DHEA) supplementation for cognitive function in healthy elderly people. Cochrane Database Syst Rev 2006;(4):CD006221.

31. Zhou Y, Su Y, Li B, et al. Nonsteroidal anti-inflammatory drugs can lower amyloidogenic Abeta42 by inhibiting Rho. Science 2003;302(5648):1215-7

32. Weggen S, Eriksen JL, Das $P$, et al. A subset of NSAIDs lower amyloidogenic Abeta42 independently of cyclooxygenase activity. Nature 2001;414(6860):212-6.

33. Breitner JC, Haneuse SJ, Walker R, et al. Risk of dementia and AD with prior exposure to NSAIDs in an elderly communitybased cohort. Neurology 2009;72(22):1899-905.

34. Sonnen JA, Larson EB, Walker RL, et al. Nonsteroidal anti-inflammatory drugs are associated with increased neuritic plaques. Neurology 2010;75(13):1203-10.

35. Szekely CA, Breitner JC, Fitzpatrick AL, et al. NSAID use and dementia risk in the Cardiovascular Health Study: role of APOE and NSAID type. Neurology 2008;70(1):17-24.

36. Szekely CA, Green RC, Breitner JC, et al. No advantage of A beta 42-lowering NSAls for prevention of Alzheimer dementia in six pooled cohort studies. Neurology 2008;70:2291-8.

37. ADAPT Research Group, Lyketsos CG, Breitner JC, et al. Naproxen and celecoxib do not prevent AD in early results from a randomized controlled trial. Neurology 2007;68(21):1800-8.

38. Haag MD, Hofman A, Koudstaal PJ, Stricker BH, Breteler MM. Statins are associated with a reduced risk of Alzheimer disease regardless of lipophilicity. The Rotterdam Study. J Neurol Neurosurg Psychiatry 2009;80(1):13-7.

39. Heart Protection Study Collaborative Group.MRC/BHF Heart Protection Study of cholesterol lowering with simvastatin in 20,536 high risk individuals:a randomised placebo-controlled trial. Lancet 2002;360(9326):7-22.

40. McGuinness B, Craig D, Bullock R, Passmore P. Statins for the prevention of dementia. Cochrane Database Syst Rev 2009;(2):CD003160

41. von Arnim CA, Gola U, Biesalski HK. More than the sum of its parts? Nutrition in Alzheimer's disease. Nutrition 2010;26(78):694-700.

42. Panza F, Frisardi V, Seripa D, et al. Alcohol consumption in mild cognitive impairment and dementia: harmful or neuroprotective? Int J Geriatr Psychiatry 2012;27(12):1218-38.

43. Maguire NC, Drozd K, Luff RD, Kantor RR. Immunohistochemical localization of glutathione S-transferase in preneoplastic and neoplastic lesions of the human uterine cervix. Acta Cytol 1991;35(1):94-9.

44. Carrie I, van Kan GA, Gillette-Guyonnet S, et al. Recruitment strategies for preventive trials. The MAPT study (MultiDomain Alzheimer Preventive Trial). J Nutr Health Aging 2012;16(4):355-9.

45. Kivipelto M, Solomon A, Ahtiluoto S, et al. The Finnish Geriatric Intervention Study to Prevent Cognitive Impairment and Disability (FINGER): study design and progress. Alzheimers Dement 2013;9(6):657-65. 
46. Richard E, Van den Heuvel E, Moll van Charante EP, et al. Prevention of dementia by intensive vascular care (PreDIVA): a cluster-randomized trial in progress. Alzheimer Dis Assoc Disord 2009;23(3):198-204.

47. Gillette-Guyonnet S, Andrieu S, Dantoine T, et al. Commentary on "A roadmap for the prevention of dementia II. Leon Thal Symposium 2008." The Multidomain Alzheimer Preventive Trial (MAPT): a new approach to the prevention of Alzheimer's disease. Alzheimers Dement 2009;5(2):114-21.

48. Sperling RA, Rentz DM, Johnson KA, et al. The A4 study: Stopping AD before symptoms begin? Sci Transl Med 2014;6(228):228fs13.

49. Worley S. After disappointments, Alzheimer's researchers seek out new paths: biomarkers and combination therapies may lead to disease-modifying treatments, experts say. P T 2014;39(5):365-74. 